\title{
Awareness Level of Poultry Husbandry Practices by the Poultry Farmers in Bhilwara District of Rajasthan, India
}

\author{
C.M. Yadav ${ }^{1,2 *}$, H.L. Bugalia ${ }^{1,2}$, Ramawtar ${ }^{1,2}$ and Bhavna Dhakar ${ }^{1,2}$ \\ ${ }^{1}$ Krishi Vigyan Kendra, Bhilwara, India \\ ${ }^{2}$ Maharana Pratap University of Agriculture and Technology, Udaipur-313001, \\ Rajasthan, India \\ *Corresponding author
}

\section{A B S T R A C T}

\section{Key words \\ Feeding, Housing, Brooding, Watering, Scientific equipment and vaccination programme}

Article Info

Accepted: 06 June 2018 Available Online: 10 July 2018
Poultry Farmers had high level of knowledge regarding poultry housing (39.17\%), brooding $(39.17 \%)$ and feeding $(42.5 \%)$ practices. Considerable number of poultry farms has grown up in Bhilwara district of Rajasthan. Hence, the knowledge of poultry practices occupies the importance. The present study was concluded in Bhilwara District of Rajasthan on 120 poultry Farmers selected by multi-stage sampling procedure. The study, utilization of mass media and attitude toward poultry rearing were the important factors concluded that a majority of the farmers had medium level of knowledge on different aspects of poultry production practices. Education, annual income, socio-economic status, flock size, extension contact which have contributed to the knowledge gained by the poultry Farmers. About 38.35 percent of the respondents used medium level of scientific equipments followed by high $(31.22 \%)$ and only 30.43 percent of respondents with low used of scientific equipments on their poultry farms.

\section{Introduction}

India has 1.23 billion people and the number is growing every year. The focus is on "Development" meaning Good Food, Better Health and Living conditions to everyone. People spend more money on food when they earn more. Healthy food at attractive price will be the issue in focus. Eggs and chicken are accepted by all communities and are available at the most reasonable prices. Poultry is the most organized sector in animal agriculture, worth rupees one lakh crores. The growth is 6-
$8 \%$ in layers and $10-12 \%$ in broilers per year against the growth of agriculture as a whole which is around $2.5 \%$.India is the third-largest egg producer after China and USA and the fourth-largest chicken producer after China, Brazil and USA. The per capita eggs consumption has gone up from 30 to 68 and the chicken from $400 \mathrm{gm}$ to $2.5 \mathrm{~kg}$. Human nutritionists recommend 180 eggs and $10 \mathrm{~kg}$ chicken per year. Most of the countries consume over 240 eggs and $20 \mathrm{~kg}$ of chicken. There is scope for enhancing the production. Production is getting more organized and 
move ahead of consumption resulting in optimum prices and with minimum profits. India has $60 \%$ rural population depending on agriculture. Poultry has been there in the backyards of most of the houses since ages, forming a part of nutrition and family income. At one time, $30 \%$ of the eggs produced were in the backyards. The birds available there were never improved and were inefficient for both eggs and meat production. Grains, fruits, flowers, vegetables and milk are all produced by the small farmers. Even the products are marketed by the farmers directly in weekly village markets and "Collection Centers" established by government or companies. Scavenging poultry birds normally maintained by women, sometime contribute as much as 80 percent of annual income to households (Anonymous, 2001).

Aware and update the grass- root level extension agencies on the latest technologies of agriculture and allied sectors in the district (Patil and Kokate, 2011). About 8 percent of GDP of the state is contributed by livestock sector alone. As per the livestock census 2012 the poultry 80.24 lacs in the state. However, high mortality, due to various diseases, constitutes one of the greatest constraints on poultry farming. Poultry production under modern technologies needs high expenditure which is very difficult to adopt for the rural farmers of Bhilwara district. Few resource rich farmers are involved in this venture. Poultry farmers should essentially passes the scientific knowledge on farming to take preventive action, identify the disease condition and various poultry management practices etc. Hence, the present study was undertaken to access the awareness level assessment of poultry husbandry practices by the poultry farmers in Bhilwara district of Rajasthan.

\section{Materials and Methods}

The present study was conducted in Bhilwara District of Rajasthan. A Multi-stage sampling procedure was followed for selection of block, village and respondent. Three block were selected randomly out of twelve (12) block from Bhilwara district of Rajasthan. Then, two village were randomly selected from each selected bock for the present study. Total 120 respondent (Poultry Farmers) were selected based on proportional random sampling method. The data were collected using structural interview scheduled. The data collected were then analyzed using statistical tools namely, frequency, percentage, mean, standard deviation, simple correlation coefficient and multiple regressions.

\section{Results and Discussion}

The result shown that in all, eight selected poultry husbandry practices were studied in terms of number of knowledge efficiency as well as the assessment and nature of knowledge efficiency of each individual practice. The result indicates that nearly half $(38.27 \%)$ of the respondent belong to high category followed by medium category $(34.73 \%)$ and low category (27\%) respectively with respect to knowledge about poultry housing practices. It shows that 38.27 percent of the respondent were having high knowledge of brooding management practices, followed by low (32.28\%) and medium (29.45\%) respectively. Since, brooding period of chick is the crucial period for enhancing the growth, productivity and low mortality of the poultry. Further 40.20 percent of poultry farmers were having high knowledge about feeding practices, followed by medium $(32.28 \%)$ and, with low $(27.52 \%)$ feeding practices. Feed intake capacity of their birds. The result is in line with the findings of Oyeyinka et al., (2011), 47.5 percent of the respondents were having medium knowledge followed by low and high level of knowledge respectively, with respect to watering practices. All the respondents however were not performing debeaking practices and deforming practices. Majority (64.10\%) of respondents belong to 
medium categories followed by low (28.15\%) and high $(7.75 \%)$ categories with regards to vaccination knowledge. About 38.35 percent of the respondents used medium level of scientific equipments followed by high $(31.22 \%)$ and only 30.43 percent of respondents with low used of scientific equipments on their poultry farms.
The determination of knowledge level on poultry production practices presented in Table 1 indicated that out of total 13 independents variables only two of them i.e., flock size and economic motivation were found to be significant at 0.01 and 0.05 level of significant respectively.

Table.1 Regression analysis of independent variables $(\mathrm{X})$ and with the knowledge level assessment of poultry husbandry practices (dependent variable-Y)

\begin{tabular}{|l|c|c|c|}
\hline \multicolumn{1}{|c|}{ Independent variables } & $\begin{array}{c}\text { Regression Co- } \\
\text { efficient 'b' }\end{array}$ & $\begin{array}{c}\text { Standard } \\
\text { error }\end{array}$ & 't' Value \\
\hline Age & -0.069 & 1.239 & -0.847 \\
\hline Family size & -0.141 & 1.442 & -1.798 \\
\hline Educational status & 0.127 & 0.464 & 1.472 \\
\hline Annual average income & -0.021 & 2.294 & -0.126 \\
\hline Socio- economic status & 0.015 & 0.691 & 0.092 \\
\hline Flock size (No.of poultry birds) & 0.462 & 1.322 & $4.792^{* *}$ \\
\hline Innovation proneness & -0.083 & 0.486 & -1.006 \\
\hline Attitude towards poultry rearing & 0.084 & 0.207 & 0.974 \\
\hline Economic motivation & -0.212 & 0.358 & $-2.752^{*}$ \\
\hline Utilization of mass media & 0.080 & 0.329 & 0.861 \\
\hline Contact with extension staff & 0.016 & 0.699 & 0.177 \\
\hline Marketing facilities & -0.005 & 0.759 & -0.066 \\
\hline Supervision of poultry farm & -0.051 & 0.384 & -0.636 \\
\hline
\end{tabular}

$* * \mathrm{P}<0.001, * \mathrm{P}<0.05, \mathrm{R}^{2}=0.382$

The estimated coefficient for flock size was positive (0.462) and has ' $t$ ' value (4.792), that implies every one percent increase in flock size, would lead to 46.6 percent increase in knowledge of poultry produced. The finding is in consonance with the result of Ezeh et al., (2012) and Effiong (2005). Economic motivation has negative coefficient of (-0.212) and has ' $t$ ' value $(-2.752)$ which indicated that increase in economic motivation reduces the level of knowledge. The $\mathrm{R}^{2}$ value (0.382) indicated that 38.2 percent was contributed towards the changes in knowledge level due to independent variables. These two variables (i.e. flock size and economic motivation) could be term as good predictor of knowledge of the poultry farmers.
In conclusion, majority $(65 \%)$ of the respondent possessed medium level of knowledge about selected poultry husbandry practices. Poultry Farmers had high level of knowledge regarding poultry housing (39.17\%), brooding (39.17\%) and feeding $(42.5 \%)$ practices. The respondents were found to have medium level of knowledge about poultry watering $(47.5 \%)$ and vaccination $(60.83 \%)$ practices. All the respondents did not practice debeaking and deworming practices. Majority $(60.83 \%)$ of the respondent was using scientific equipments on their poultry farms. Education, annual average income, socio-income status, flock size, attitude toward poultry rearing, 
utilization of mass media and, contact with extension staff were significantly and positively related with the knowledge level of poultry Farmers. In determination of regression analysis it was found that out of total 13 independent variables only two variables i.e. flock size and economic motivation were significant at 0.01 and 0.05 Level of significant respectively. A very strong and robust finding of the study is that about 40 percent was contributed towards changes in knowledge level due to independent variables in the model.

The study concluded that majority of the farmers had medium level of knowledge on different aspects of poultry production practices. Education, annual average income, socio-economic status, flock size, extension contact, utilization of mass media and attitude toward poultry rearing were the important factors which have contributed to the knowledge gained by the poultry farmers.

\section{References}

Anonymous, 2001. Report on scavenging poultry information gathered jointly by Bharatiya agro industrial foundation (BAIF). Department of Animal Husbandry (Gujarat, Rajasthan, Tamil Nadu). TNUVAS and Sac.

Effiong, E.O. 2005. Efficiency of production in selected livestock enterprises in Akwa-Ibom State, Nigeria. Ph.D. Thesis, Dept. of Agricultural Economics, Michael Okpara University of Agriculture, Umudike.

Ezeh, C. I., Anyiro, C.O. and Chukwu, J.A.2012. Technical Efficiency in Poultry Broiler Production in Umuahia Capital Territory of Abia State, Nigeria. Greenner Journal of Agricultural Sciences. 2 (1), pp.001007.

Livestock census 2012. $19^{\text {th }}$ Livetock Census, Department of Animal Husbandry. Government of Rajasthan.

Patil, S.S. and Kokate, K.D. 2011. Training needs assessment of subject matter specialists of Krishi Vigyan Kendras. Indian Research Journal of Extension Education29: 20-25.

\section{How to cite this article:}

Yadav, C.M., H.L. Bugalia, Ramawtar and Bhavna Dhakar. 2018. Awareness Level of Poultry Husbandry Practices by the Poultry Farmers in Bhilwara District of Rajasthan. Int.J.Curr.Microbiol.App.Sci. 7(07): 421-424. doi: https://doi.org/10.20546/ijcmas.2018.707.051 